\title{
Contribuições do Plano de Ações Articuladas às políticas de valorização docente em municípios brasileiros ${ }^{1}$
}

\section{Contributions of Articulated Actions Plan to teacher valorization policies in Brazilian municipalities}

\author{
Contribuciones delPlan de AccionesArticuladas a las \\ políticas de reconocimiento a los maestros en los \\ municipios brasileños
}

\section{Elisangela Alves da Silva Scaff² Fabiana Rodrigues dos Santos ${ }^{3}$}

\section{Resumo}

O presente texto discute as contribuições do Plano de Ações Articuladas (PAR) para a efetivação de conquistas relativas à valorização docente. O lócus da pesquisa é constituído por cinco municípios do estado de Mato Grosso do Sul, nos quais foi realizado levantamento documental e entrevistas com os coordenadores do PAR. Tomou-se com fonte secundária, jornais eletrônicos dos municípios. Os dados apontam que o PAR desempenha importante papel na indução dos municípios à regulamentação das normativas atinentes à valorização docente, no entanto, o estabelecimento do compromisso por parte dos municípios nem sempre se reverte em ações voltadas ao seu cumprimento.

Palavras-chave: Planejamento Educacional; Valorização Docente; Plano de Ações Articuladas.

\begin{abstract}
This paper discusses the contributions of the Articulated Actions Plan (PAR) for achieving gains on the teacher appreciation. The research locus consists of five municipalities in the state of Mato Grosso do Sul, where it was held documentary survey and conducted interviews with the PAR coordinators. As secondary source, electronic newspapers of the municipalities. The data indicate that the PAR has played an important role in the induction of federative sites regarding to the regulation of rules relating to teacher appreciation, however, the establishment of the commitment by the municipalities not always reverts into actions to its compliance.
\end{abstract}

Keywords: Educational Planning; Teacher Appreciation; Articulated Actions Plan. 


\section{Resumen}

Este artículo analiza las contribuciones del Plan de AccionesArticuladas (PAR) para la realización de ellogro de la apreciación de los docentes. El locus de la investigación consiste en cinco municipios en el estado de Mato Grosso do Sul, en el que se llevó a cabo la encuesta documental y entrevistas con los coordinadores del PAR. Se llevó con fuente secundaria periódicos electrónicos de los municipios. Los datos indican que el PAR juega un papel importante en la inducción de los municipios para la regulación de los reglamentos relacionados con la apreciación del profesor, sin embargo, el compromiso del establecimiento por los municipios no siempre vuelve a las acciones encaminadas a su cumplimiento.

Palabras clave: Planificación de la Educación;Apreciación del profesor; Plan de AccionesArticuladas.

\section{Introdução}

As reformas educacionais realizadas pelo governo brasileiro na década de 1990 têm vinculadoa busca da qualidade do ensino ao desempenho dos docentes, de forma que esse tema vem merecendo crescente atenção na agenda das políticas públicas, o que abre perspectivas promissoras para sua valorização (BALZANO, 2007).

Na esfera legal, a Constituição Federal de 1988 define os princípios e orientações gerais para a valorização do magistério em seu artigo 206, inciso V, que preconiza a "valorização dos profissionais da educação escolar, garantidos, na forma da lei, planos de carreira, com ingresso exclusivamente por concurso público de provas e títulos, aos das redes públicas"(BRASIL,1988).

A Lei de Diretrizes e Bases da Educação (LDB) Lei n.9394/1996 prescreve que os sistemas de ensino devem promover a valorização dos profissionais da educação a partir do piso salarial profissional nacional, aperfeiçoamento contínuo, condições adequadas de trabalho, progressão funcional, entre outros (BRASIL, 1996a).

O Fundo de Manutenção e Desenvolvimento da Educação Básica e de Valorização dos Profissionais da Educação (Fundeb) 4 garante, por meio de seu mecanismo de distribuição de recursos, que a maior parte das receitas vinculadas à educação, no âmbito dos Estados, Distrito Federal e Municípios, seja aplicada na educação básica (educação infantil, ensino fundamental e médio e em suas diversas modalidades) e na valorização dos profissionais em educação, promovendo uma melhor distribuição destes recursos.

A Lei $n^{\circ} 11.738 / 2008$ que institui e regulamenta o Piso Salarial Profissional Nacional para os profissionais do magistério público da Educação Básica em seu artigo $2^{\circ}$, inciso IV, reconhece que o trabalho docente não se limita à sala de aula e, portanto, afirma a obrigatoriedade de composição da jornada de trabalho observando-se o limite máximo de 2/3 (dois terços) da carga horária para desempenho das atividades de interação com os educandos (Brasil, 2008b). Embora essas legislações tenham registrado avanços em relação ao tema em nível nacional, no plano local ainda são muitos os desafios atinentes à implantação da referida Lei. Exemplo disso está na Ação Direta de Inconstitucionalidade (ADI) movida por governadores de vários estados brasileiros em 2008 e julgada improcedente pelo Supremo Tribunal Federal (STF) no ano de 2011.

A resistência ou incapacidade dos entes federativos em cumprir com o estabelecido pela Lei 11.738/2008 tem gerado disparidades no que se refere ao salário e carreira entre os diferentes estados, Distrito Federal e os mais de cinco mil municípios existentes no país, sendo este um entre vários aspectos que interferem na qualidade educacional pretendida, segundo estabelece o Plano de Metas Compromisso Todos pela 
Educação, ao definir como uma de suas 28 metas: "XIII - implantar plano de carreira, cargos e salários para os profissionais da educação, privilegiando o mérito, a formação e a avaliação do desempenho" (BRASIL, 2007).

A fim de conferir materialidade às diretrizes estabelecidas por tal plano em âmbito local, o Ministério da Educação (MEC)criou o Plano de Ações Articuladas (PAR), por meio do Decreto n 6.094/2007, "...instrumento jurídico para a consolidação de um regime de colaboração entre a União e os entes federativos" (FERREIRA, 2014, p.614) que estabelece apoio técnico e financeiro aos estados e municípios para que cumpram as metas do Compromisso Todos pela Educação.

Passados mais de cinco anos desde a assinatura de tal Compromisso por todos os entes federativos brasileiros, desenvolveu-se pesquisa com o objetivo de analisar as contribuições do PAR em relação à valorização docente no que diz respeito a duas categorias: remuneração e carreira. O lócus da pesquisa é constituído por cinco municípios de Mato Grosso do Sul, assim distribuídos: 02 municípios com população abaixo de 50 mil habitantes (Naviraí e Coxim), 1 município com população entre 51 e 100 mil habitantes (Ponta Porã) e 2 municípios com população acima de 100 mil habitantes (Dourados e Corumbá).

A pesquisa foi desenvolvida por meio de levantamento documental realizado nos cinco municípios selecionados, contemplando especificamente os Planos de Ações Articuladas elaborados pelos municípios para o período de 2011 a 2014 e os planos de carreira dos profissionais de educação vigentes, de forma a estabelecer relações entre eles. Realizou-se também entrevistas com os coordenadores do Plano de Ações Articuladas (PAR) nos cinco municípios, com vistas a identificar a relação que se estabelece no circuito local entre ambos os planos em análise. Tomou-se com fonte secundária os jornais eletrônicos dos municípios e da região, a fim de apreender o movimento de negociação entre os sindicatos municipais e as Prefeituras no processo de concretização da política de valorização docente nos municípios em análise.

\section{Perspectivas de valorização docente a partir da década de 1990}

Condição essencial para a efetivação das políticas para a valorização docente está na regulamentação da carreira e remuneração, ou seja, uma carreira regulamentada e um Piso Salarial Profissional Nacional (PSPN) são elementos fundamentais para o reconhecimento da docência como profissão e a desvinculação da representação que se fez (e se faz) do ensino comovocação e missão (DUARTE, 2013). Essa representação colaborou sobremaneira para o afastamento social da categoria dos professores como profissionais que lutam por seu sustento.

O Parecer n. 9/2012, elaborado pela Câmara de Educação Básica do Conselho Nacional de Educação (CEB/CNE), ressalta a especificidade desse trabalho ao declarar que se trata de uma profissão que tem como objetivo formar cidadãos comprometidos com a transformação que a sociedade necessita. Esse Parecer fornece suporte às ações de reconhecimento e valorização social à docência, expressas pela oferta de uma carreira digna e uma remuneração apropriada ao trabalho deles esperado (GATTI; BARRETO, 2009). Nesta direção, a questão salarial docente se associa à discussão sobre a qualidade da educação no país e a atratividade da carreira e permanência nela, afinal, como afirmam Gatti e Barreto (2009), não é banal a perda de bons quadros profissionais que poderiam atuar nas escolas em favor de outras áreas profissionais.

O estudo realizado por Alves e Pinto (2011) confirma a remuneração insatisfatória de professores, sobretudo na comparação com outras profissões, o que pode ter influenciado na mudança no perfil dos sujeitos que buscam a profissão docente. Os dados consolidados nas análises do Exame Nacional do Ensino Médio indicam, entre os alunos que escolhem o magistério como profissão, aqueles que têm dificuldade 
com a língua, com a leitura e escrita e compreensão de texto, a maioria oriunda de famílias das classes C e D, proveniente dos sistemas públicos de ensino e que tem apresentado, nas diferentes avaliações, um baixo desempenho, ou seja, alunos que tiveram dificuldades para chegar ao ensino superior, estudantes que, principalmente pelas restrições financeiras, tiveram pouco acesso aos bens culturais, como cinema, teatro e outros (GATTI et all, 2009).

Pesquisa coordenada por Gatti (2009) comprova que a falta de atratividade na carreira tem colaborado para que o ingresso nas licenciaturas tenha como público alunos com baixo potencial acadêmico. A autora aponta que a carreira docente mostrou-se mais atraente para jovens de um segmento social desfavorecido, que muitas vezes é acompanhado de uma escolarização precária, aspecto que deve ser enfrentado pelos cursos de formação inicial de professores e pelas políticas que os orientam (GATTI et all, 2009, p. 73).

Outro elemento que contribui para a pouca atratividade da carreira docente é a remuneração. Kuenzer e Caldas (2009) analisam que em função dos baixos salários, muitas vezes, os professores são obrigados a ampliar a jornada de trabalho, atuando em diversas escolas. As autoras afirmam que essa ampliação do tempo de trabalho, somada à diversificação de tarefas, faz com que os professores encontrem cada vez mais dificuldades na sua atuação profissional, deixando de lado a luta por melhores condições de trabalho e buscando simplesmente tempo para descanso.

Introduzido na Constituição Federal de 1988 como princípio, o Piso Salarial Nacional Docente (PSPN) se inscreve como uma das principais alternativas para a redução das desigualdades existentes no Brasil em relação à remuneração docente. Sua função social vai além da valorização salarial dos profissionais do magistérioe se configura como um instrumento capaz de alterar a organização da escola por meio de uma maior disponibilidade desses profissionais na construção de melhores perspectivas de qualidade (MACHADO, 2010).

A Lei n. 11.738, de 16 de julho de 2008 que institui o PSPN, materializa um importante passo na mobilização em torno do reconhecimento e da valorização social do magistério. A chamada "Lei do Piso" veio regulamentar a carreira do magistério público em face do cumprimento aos dispositivos legais constantes na Constituição Federal de 1988 e na Lei n 11.494/2007 que regulamentou o Fundeb originando, a posteriori, a Resolução do CNE, n 02/2009 que aponta diretrizes técnicas sobre a profissão docente e os planos de carreira e remuneração.

O vencimento inicial estabelecido pela Lei 11.738 para o ano de 2008 é de $\mathrm{R} \$ 950,00$ (Novecentos e Cinquenta Reais) para uma jornada de trabalho de até 40 horas semanais de um docente com formação em nível médio. O reajuste do piso é fixado anualmente, utilizando-se para seu cálculo o mesmo percentual de crescimento do valor anual mínimo por aluno referente aos anos iniciais do ensino fundamental urbano, definido nacionalmente, nos termos da Lei n. ${ }^{0} 11.494$, de 20 de junho de $2007^{5}$ (BRASIL, 2007a).

A data limite estabelecida para que os entes federados elaborem ou adequem seus planos de carreira e remuneração do magistério foi o dia 31 de dezembro de 2009. Diante dessa determinação legal, questionouse por meio dos dados levantados nesta pesquisa: Entre os municípios selecionados, quais cumprem com a lei do piso no que se refere à remuneração docente? Quais cumprem a referida lei no que diz respeito ao tempo destinado à hora atividade? Quais elaboraram ou reelaboraram os planos de carreira docente? Quais as contribuições do PAR para a efetivação da valorização docente nos municípios pesquisados? Essas questões nortearão a segunda parte deste texto.

5 Em janeiro de 2015, o valor do piso foi reajustado para $\mathbf{R} \$ 1.917,78$ (Um mil, novecentos e dezessete reais e setenta e oito centavos), conforme determina 0 Artigo $5^{\circ}$ da Lei No. 11.738/2008. 


\section{Valorização docente em municípios sul-mato-grossenses: contribuições do PAR}

O PAR, instituído pelo Decreto No. 6.094/2007, estabelece apoio técnico e financeiro do Ministério da Educação aos estados e municípios brasileiros a fim de viabilizar o cumprimento das metas do Compromisso Todos pela Educação. O documento "Orientações gerais para a elaboração do PAR" (BRASIL, 2008b) detalha o processo de elaboração pelos entes federativos, que ocorre em duas fases distintas, primeiramente os estados e municípios desenvolvem o "Levantamento da Situação Escolar - LSE", a ser realizado por uma comissão técnica local constituída por sujeitos sociais do segmento educacional, tais como dirigente municipal de educação, técnicos da secretaria municipal de educação e representantes dos diretores de escola, dos professores da zona urbana e da zona rural, dos coordenadores ou supervisores escolares, do quadro técnico-administrativo das escolas, dos Conselhos Escolares e, quando houver, do Conselho Municipal de Educação. Tal levantamento é elaborado por meio de preenchimento de um formulário no Sistema Integrado de Planejamento, Orçamento e Finanças do Ministério da Educação (Simec), que o Ministério da Educação disponibiliza em seu sitio eletrônico.

Os indicadores a serem contemplados pelos munícipios estão organizados em torno das seguintes dimensões: 1) gestão educacional; 2) formação de professores e profissionais de serviços e apoio escolar; 3) recursos pedagógicos; e 4) infraestrutura física das instituições escolares. Cada uma dessas quatro dimensões se subdivide em áreas, e cada área comporta diversos indicadores, como evidencia o detalhamento da Dimensão 1, subdividida em cinco áreas e vinte e oito indicadores, quais sejam:

Área 1 - Gestão Democrática: Articulação e Desenvolvimento dos Sistemas de Ensino (7 indicadores).

Área 2 - Gestão de pessoas (9 indicadores)

Área 3 - Conhecimento e utilização de informação (6 indicadores)

Área 4 - Gestão de finanças (3 indicadores)

Área 5 - Comunicação e interação com a sociedade (3 indicadores) (BRASIL, 2011, p. 28).

O preenchimento do formulário no SIMEC consiste em atribuir nota aosindicadorespré-estabelecidos em cada dimensão. As notas atribuídas vão de um a quatro, de acordo com os seguintes critérios:

Critério de Pontuação 4 - A descrição aponta para uma situação positiva e não são necessárias ações imediatas. 0 que a Secretaria de Educação realiza na(s) área(s) pertinente(s) garante bons resultados nesse indicador.

Critério de Pontuação 3 - A descrição aponta para uma situação favorável, porém o município pode implementar ações para melhorar 0 seu desempenho.

Critério de Pontuação 2 - A descrição aponta para uma situação insuficiente, e serão necessárias ações planejadas de curto, médio e longo prazos para elevar a pontuação nesse indicador

Critério de Pontuação 1 - a descrição aponta para uma situação crítica, e serão necessárias ações imediatas, além do planejamento de médio e longo prazos, para superação dos desafios apontados no diagnóstico da realidade local (BRASIL, 2011, p. 29-30).

Para este texto interessa identificar a pontuação atribuída pelos municípios selecionados a dois indicadores da dimensão 1 (Gestão Educacional), área 2 (Gestão de Pessoas): indicadores 6 (Planos de Carreira) e 8 (Piso salarial nacional do professor). 


\section{Quadro 1: Informações do PAR 2011 - 2014 dos municípios quanto ao indicador 6 (Plano de carreira para o magistério) da dimensão 1 (Gestão Educacional)}

\begin{tabular}{|c|c|c|c|}
\hline Município & Diagnóstico & Justificativa & Demanda \\
\hline Corumbá & \multirow{2}{*}{$\begin{array}{c}3 \text { - Quando o plano de carreira para o magistério } \\
\text { está em fase de implementação; expressa } \\
\text { com clareza uma concepção de valorização do } \\
\text { magistério para a qualidade da educação escolar, } \\
\text { mas não é de conhecimento da comunidade. } 0 \\
\text { plano estabelece regras claras para ingresso na } \\
\text { carreira (por concurso público), avaliação de } \\
\text { desempenho e critérios de evolução funcional por } \\
\text { meio de trajetória de formação (formação inicial e } \\
\text { continuada) e tempo de serviço; assim como prevê } \\
\text { composição da jornada de trabalho com hora-aula e } \\
\text { hora-atividade. }\end{array}$} & $\begin{array}{l}\text { Está em tramitação na } \\
\text { Câmara Municipal. }\end{array}$ & $\begin{array}{l}\text { Assim que estiver aprovado } \\
\text { colocar o plano em prática. }\end{array}$ \\
\hline Coxim & & $\begin{array}{l}\text { Existe o PCCR (plano } \\
\text { de cargos e carreiras } \\
\text { e remuneração) } \\
\text { porém não contempla } \\
\text { aspectos da avaliação de } \\
\text { desempenho docente ao } \\
\text { longo de sua carreira }\end{array}$ & $\begin{array}{l}\text { Assegurar no PCCR critérios } \\
\text { de avaliação de desempenho } \\
\text { docente ao longo de sua carreira. } \\
\text { Necessidade do cumprimento, } \\
\text { pelos dirigentes, da legislação } \\
\text { vigente. }\end{array}$ \\
\hline Dourados & \multirow{2}{*}{$\begin{array}{c}4 \text { - Quando existe plano de carreira para o } \\
\text { magistério implementado; ele expressa com } \\
\text { clareza uma concepção de valorização do } \\
\text { magistério para a qualidade da educação escolar, } \\
\text { sendo de conhecimento da comunidade. } 0 \\
\text { plano estabelece regras claras para ingresso na } \\
\text { carreira (por concurso público), avaliação de } \\
\text { desempenho e critérios de evolução funcional por } \\
\text { meio de trajetória de formação (formação inicial e } \\
\text { continuada) e tempo de serviço; assim como prevê } \\
\text { composição da jornada de trabalho com hora-aula e } \\
\text { hora-atividade. }\end{array}$} & $\begin{array}{l}\text { Existe um plano } \\
\text { de carreira para o } \\
\text { magistério, está em } \\
\text { reformulação para } \\
\text { atender o Parecer } \\
\text { 09/2009 e a Resolução } \\
\text { 03/97 CEB/CNE. }\end{array}$ & $\begin{array}{l}\text { Garantir a efetiva implementação } \\
\text { do plano de carreira para o } \\
\text { magistério e demais profissionais } \\
\text { da educação, que promova a } \\
\text { valorização e a formação desses } \\
\text { profissionais e qualidade social da } \\
\text { educação escolar. }\end{array}$ \\
\hline Ponta Porã & & Não há. & $\begin{array}{l}\text { Haverá estudos para revisão do } \\
\text { Plano de Cargos e Carreira do } \\
\text { Magistério, tendo em vista a nova } \\
\text { Política Nacional de Educação. }\end{array}$ \\
\hline Naviraí & Indicador não contemplado no PAR do Município & & \\
\hline
\end{tabular}

Fonte: Elaborado para esta pesquisa com base nos seguintes documentos CORUMBÁ, 2011; COXIM, 2011; DOURAD0S, 2011; NAVIRAÍ, 2011; PONTA PORÃ, 2011.

A partir do diagnóstico e da demanda prevista,quatro municípios apontam como ação a ser desenvolvida "Garantir a publicização do plano de carreira para o magistério e assegurar as condiçõespara a sua implantação na rede municipal de ensino." Para efetivar tal ação, elencam três sub-ações, quais sejam: a) Elaborar minuta do projeto de lei para proposição de alterações no plano de carreira para o magistério da rede municipal de ensino; e encaminhá-lo para aprovação na CâmaraMunicipal; b) Mobilizar os integrantes da Câmara Municipal para aprovação do projeto de lei que trata do plano de carreira para o magistério da rede municipal de ensino; c) Tornar público, após a aprovação do projeto de lei, o plano de carreira para o magistério da rede municipal de ensino.

Observa-se que as ações e sub-ações são enunciadas por meio de texto padrão, ou seja, para cada diagnóstico realizado, o próprio formulário aponta a ação a ser desenvolvida pelo município, o que evidencia a indução do governo federal aos municípios, que devem se comprometer com a elaboração de projeto de lei, bem como com a mobilização do poder legislativo municipal para sua aprovação e divulgação para a comunidade.Ressalte-se que o município de Naviraí não apresenta diagnóstico ou ações para esse indicador, no entanto, em levantamento realizado em 2014, apenas Naviraí e Corumbá cumpriram com o compromisso firmado no PAR, como evidencia o quadro 2. 
Quadro 2: Planos de Carreira dos Profissionais da Educação nos municípios pesquisados (2015)

\begin{tabular}{|c|c|c|}
\hline Município & Lei & Data \\
\hline Corumbá & $\begin{array}{l}\text { Lei Complementar } N^{0} 150 \text {, institui o Plano de Carreira e Remuneração do } \\
\text { Magistério Municipal de e dispõe sobre direitos, vantagens e obrigações de } \\
\text { seus integrantes. }\end{array}$ & 4 de abril de 2012 \\
\hline Coxim & $\begin{array}{l}\text { Lei complementar 023, dispõe sobre o Plano de Cargos, Carreiras e } \\
\text { Remuneração do Grupo Trabalhadores da Educação Básica de Coxim-MS }\end{array}$ & 27 de abril de 2000 \\
\hline Dourados & $\begin{array}{l}\text { Lei complementar n. 118, dispõe sobre o Plano de Cargos, Carreira e } \\
\text { Remuneração do Profissional da Educação Municipal de Dourados. }\end{array}$ & 31 de dezembro de 2007 \\
\hline Naviraí & $\begin{array}{l}\text { Lei Complementar n0 110, dispõe sobre o Estatuto dos Profissionais da } \\
\text { Educação Básica do Município de Naviraí. }\end{array}$ & 15 de dezembro de 2011 \\
\hline Ponta Porã & $\begin{array}{c}\text { Lei Complementar } n^{\circ} \text { 029, dispõe sobre o Plano de Cargos, Carreiras e } \\
\text { Remuneração dos servidores do Magistério Municipal do Quadro Permanente } \\
\text { da Prefeitura Municipal de Ponta Porã. }\end{array}$ & 04 de janeiro de 2006 \\
\hline
\end{tabular}

Fonte: Elaborado para esta pesquisa com base nos seguintes documentos CORUMBÁ, 2011; COXIM, 2011; DOURAD0S, 2011; NAVIRAÍ, 2011; PONTA PORÃ, 2011.

Ocoordenador entrevistado no município de Corumbá destaca a contribuição do PAR na reformulação dos Planos de Cargos e Carreira "[...]nas ações do PAR também está a construção de todo o nosso Plano de Cargos e Carreiras" (COORDENADOR - PAR - CORUMBÁ).

Nos municípios em que esse processo não foi finalizado, os coordenadores entrevistados reconheceram tal prerrogativa estabelecida nos documentos do PAR e esclarecem, como no município de Dourados, que esse processo encontra-se em andamento, mas ainda não foi encaminhado ao legislativo. Observase assim, que a exigência preconizada no PAR a respeito da reformulação dos planos de carreira tem contribuído no sentido de colocar em pauta essa questão para os municípios, apontando avanços necessários na reformulação de tais planos, como evidencia o depoimento do coordenador do município de Corumbá.

[...] ... o PAR nos mostrou também essas ações de ter cada profissional adequado à sua área de atuação no seu nível correto, as questões de concurso que lá se fala, têm ações que falam da questão ser concursado, hoje em dia nós temos pouquíssimos contratados, hoje nós temos concursos constantes (COORDENADOR - PAR - CORUMBÁ).

A análisedos planos de carreira permite constatar que todos os municípios são unânimes em determinar que o ingresso do docente na rede de ensino se dará por intermédio de concurso público de provas e títulos. 
O plano do município de Dourados, por exemplo, dispõe no Capítulo I art.13, inciso $1^{\circ}$ 凶que fica obrigatória a realização de concurso público quando as vagas alcançarem 20\% (vinte por cento) do número de cargos (DOURADOS, 2007, p.10).

Ainda assim, o último concurso público ocorrido no município foi no ano de 2006, motivo pelo qual foi instaurado inquérito civil pela Promotoria Pública de Dourados, resultando em Termo de Ajustamento de Conduta (TAC) firmado entre a Prefeitura e o Ministério Público Estadual, pelo qual o município fica obrigado a realizar abertura de concurso público no ano de 2015, com nomeação até o final do ano de 2016. Notícia de jornal local informa que "Pelo menos 848 contratados da Prefeitura de Dourados terão que ser substituídos por concursados [...] somente na área da Educação, cerca de 57\% dos servidores são cargos de confiança" (ARAÚJO, 2015).

Processo similar foi instaurado contra o município de Ponta Porã, como afirma a notícia postada em 11 de setembro de 2014, em jornal local. Intitulada "MPE recomenda que prefeito de Ponta Porã abra concurso público para professores", a matéria informa que"Há atualmente, conforme documento acostado no Inquérito Civil 040/2013, 112 professores contratados temporariamente para prover as vagas puras existentes na rede de ensino"(MIDIAMAX, 2014).

Verifica-se, nesse caso, a distância entre uma Lei de dimensão nacional que deve obrigatoriamente ser cumprida em nível municipal, as intenções dos sujeitos envolvidos na elaboração dos Planos de Carreira Docente e a ação do poder executivo municipal, revelando um campo de força repleto de conflitos e tensões que perpassam o processo de implementação de uma política, o qual, como alerta Draibe (2001) “... repousa em orientações e preferencias, envolvendo cálculos estratégicos, escolhas e decisões, por parte dos agentes que conduzem e o implementam, ou dele se beneficiam"(2001, p. 13).

Com base na análise dos planos de carreira docente dos cinco municípios, verifica-se que somente o município de Naviraí cumpre com a Lei n. 11.738/2008 quanto a Jornada de Trabalho de 1/3 de hora atividade. Corumbá não especifica o número de horas atividades e Dourados estabelece 8 horas atividades para jornada de 40 horas e 4 horas atividades para uma jornada de 20 horas. Já Ponta Porã apresenta 20\% de horas atividades de acordo com cada jornada de trabalho.

Tal informação não se confirma no levantamento realizado pela Federação dos Trabalhadores em Educação do Mato Grosso do Sul (FETEMS), ao divulgar o Ranking 2015 referente aos salários dos profissionais do magistério público da rede Estadual e Municipal de ensino de todos os municípios do estado sul-mato-grossense ${ }^{6}$. Tal ranking informa que a totalidade de municípios contemplados por esta pesquisa afirmam cumprir com a carga de $1 / 3$ para as horas atividades.

Ainda que as informações disponibilizadas pelos municípios sejam verídicas, a inexistência de garantia legal, por meio de reelaboração dos planos de carreira dos professores das redes municipais de ensino, fragiliza o direito desses profissionais, uma vez que pode ser revogado a depender das condições políticas e econômicas dos entes federativos locais.

Quanto ao Piso Salarial Profissional Nacional Docente (PSPN), o mesmo ranking divulgado pela FETEMS informa que apenas três municípios partícipes desta pesquisa (Ponta Porã, Naviraí e Dourados) cumprem com a Lei 11.738/2008, e dois municípios (Coxim e Corumbá) encontram-se entre aqueles que não efetivaram o reajuste do piso em 2015 ou não prestaram informações.

Essa questão é também contemplada no PAR dos municípios, cujos dados de preenchimento podem ser examinados no quadro 3.

6 Segundo a FETEMS a elaboração desse ranking se baseia em informações obtidas junto aos Sindicatos Municipais de Profissionais da Educação e Secretarias Municipais de Educação. 


\section{Quadro 3: Informações do PAR 2011 - 2014 dos municípios quanto ao indicador 8 (Piso salarial nacional do professor) da dimensão 1 (Gestão Educacional)}

\begin{tabular}{|c|c|c|c|c|}
\hline Município & Diagnóstico & Justificativa & Demanda & Prazo \\
\hline Corumbá & \multirow{3}{*}{$\begin{array}{l}3 \text { - Quando existe o piso salarial para } \\
\text { os profissionais do magistério, com } \\
\text { valor referenciado na Lei } 11.738 / 08, \\
\text { devidamente implementado. A } \\
\text { legislação municipal que criou o piso } \\
\text { salarial expressa, com clareza, uma } \\
\text { concepção de carreira: estabelece } \\
\text { critérios de atualização anual dos } \\
\text { valores e de evolução funcional, } \\
\text { considerando os níveis de formação } \\
\text { dos profissionais, mas não institui uma } \\
\text { carga horária mínima para atividades } \\
\text { de planejamento, coordenação e } \\
\text { trabalho coletivo; o ato normativo é do } \\
\text { conhecimento de todos. }\end{array}$} & $\begin{array}{l}\text { Ainda não existe critérios de } \\
\text { atualização anual dos valores. }\end{array}$ & Municipal & $30 / 12 / 2014$ \\
\hline $\begin{array}{l}\text { Ponta } \\
\text { Porã }\end{array}$ & & $\begin{array}{l}0 \text { município não instituiu a } \\
\text { carga horária mínima para a } \\
\text { atividade de planejamento. }\end{array}$ & $\begin{array}{l}\text { Implantar a carga horária } \\
\text { mínima para a atividade de } \\
\text { planejamento. }\end{array}$ & $30 / 12 / 2013$ \\
\hline Coxim & & $\begin{array}{c}0 \text { piso salarial foi implantado, } \\
\text { porém a carga horária } \\
\text { mínima para a atividade } \\
\text { de planejamento ainda não } \\
\text { está adequada à Lei No. } 11 . \\
738 / 2008 .\end{array}$ & $\begin{array}{c}\text { Necessidade de adequação } \\
\text { da carga horária mínima à Lei } \\
\text { No. } 11.738 / 2008 \text {, incluindo } \\
\text { os profissionais de serviço e } \\
\text { apoio escolar. }\end{array}$ & $30 / 12 / 2014$ \\
\hline Dourados & $\begin{array}{c}1 \text { - Quando não existe piso salarial } \\
\text { para professores referenciado na Lei } \\
11.738 / 08 \text {. }\end{array}$ & $\begin{array}{c}\text { Existe um piso salarial } \\
\text { para professores, porém } \\
\text { não referenciado na Lei } \\
11.738 / 08 . \text { Não está } \\
\text { regulamentado em lei } \\
\text { municipal e nem as demais } \\
\text { situações previstas no item } \\
\text { n. }{ }^{\circ} 2 .\end{array}$ & $\begin{array}{l}\text { Garantir a implementação da } \\
\text { Lei } 11.738 / 08 \text {. De acordo } \\
\text { com a especificidade do } \\
\text { município, garantir por meio } \\
\text { de legislação municipal, a } \\
\text { implantação do piso nacional } \\
\text { para } 20 \text { horas. }\end{array}$ & $30 / 12 / 2013$ \\
\hline Naviraí & $\begin{array}{l}\text { Indicador não contemplado no PAR do } \\
\text { Município }\end{array}$ & & & \\
\hline
\end{tabular}

Fonte: Elaborado para esta pesquisa com base nos seguintes documentos CORUMBÁ, 2011; COXIM, 2011; DOURADOS, 2011; NAVIRAÍ, 2011; PONTA PORÃ, 2011.

Observa-se no quadro 2 que somente o município de Dourados informa não existir piso salarial para professores referenciado na Lei 11.738/08. O município de Naviraí não apresenta informações sobre esse indicador, e os demais municípios afirmam atender parcialmente à legislação, sendo que o município de Corumbá não teria estabelecido critérios de atualização dos valores e os municípios de Ponta Porã e Coxim não atenderiam ao 1/3 de hora atividade.

Os três municípios com diagnóstico 3 prevêem como ação diante da situação diagnosticada "Garantir a publicização da legislação vigente que trata do piso salarial municipal para osprofissionais do magistério e assegurar as condições para a sua implantação na rede municipal de ensino". Para tanto, estabelecem as seguintes subações: a) Consolidar um documento, após a aprovação do ato legal que trata do piso salarial na redemunicipal de ensino, para divulgação; b) Elaborar o ato legal para instituir o piso salarial na rede municipal de ensino.

Já o município de Dourados, com diagnóstico situacional 1, indica como ação prevista "Promover o debate com os diversos segmentos do governo municipal e sociedade civil parapropor a implantação do piso salarial para os profissionais do magistério na rede municipalde ensino". As subações elaboradas pelo município são: a) Consolidar um documento, após a aprovação do ato legal que trata do piso salarial na rede municipal de ensino, para divulgação; b) Elaborar o ato legal para instituir o piso salarial na rede municipal de ensino; c) Elaborar o ato legal para proposição de alterações na legislação vigente que trata do pisosalarial municipal.

Identifica-se a contribuição do PAR na consolidação desse direito, como declara o coordenador entrevistado do município de Ponta Porã, que ressalta também o importante papel desempenhado pelo sindicato de professores:

[...]é uma ação prevista no PAR essa valorização tanto financeira por conta do piso salarial, da formação como estímulo, a formação né, mas uma questão dessa busca/luta do profissional que feita pelo sindicato, acho que tudo isso contribuiu pra melhoria das condições, porque a gente teve a implantação, por exemplo, do um terço de hora atividade na rede municipal (COORDENADOR - PAR - PONTA PORÃA, 2014). 
Notícia divulgada no site da FETEMS reforça o protagonismo sindical ao anunciar, em maio de 2013: "FETEMS na Estrada: Piso Salarial Nacional é tema de debate em Ponta Porã" (FETEMS, 2013). A reportagem relata as discussões realizadas pela Federação, junto ao sindicato municipal e a prefeitura, pelas quais se registrou avanços em relação ao cumprimento coma "Lei do Piso".

No município de Dourados, no entanto, a previsão das ações no PAR não foi suficiente para a concretização de avanços em relação ao piso salarial docente, uma vez que o projeto que instituiu o piso salarial para 20 horas semanais aos professores somente foi aprovado em 2014, após o indicativo de greve dos profissionais da educação municipal e intensos debates realizados entre o Sindicato Municipal dos Trabalhadores em Educação do Município de Dourados (SIMTED) e os poderes executivo e legislativo do município.

Saliente-se o fato de que o único município em análise a cumprir com os dois indicadores em análise - Plano de carreira para o magistério e Piso salarial docente - não contemplou essa demanda no Plano de Ações Articuladas (2011-2014), embora o coordenador do PAR informe conhecer as orientações do referido plano quanto a esses indicadores e aponte tais orientações como fundamentais no processo de consolidação desses avanços.

\section{Apontamentos Finais}

Os anos que se seguem à promulgação da Constituição Federal de 1988 vêm marcar um período de inúmeros avanços em relação à garantia de direitos com vistas à efetivação da valorização dos profissionais da educação, no caso particular aqui analisado, do profissional docente.

Tal processo tem início com a Carta Magna, que vincula a valorização dos profissionais da educação à elaboração de planos de carreira e ingresso exclusivamente por concurso público, e culmina com a aprovação da Lei n. 11.738/2008 que regulamenta o Piso Salarial Profissional Nacional para os profissionais do magistério público da educação básica.

Ao mesmo tempo em que tais leis registram avanços primordiais para a categoria, também anunciam imenso desafio, uma vez que sua efetivação está sujeita a regulamentação por parte dos entes federativos locais. Instrumento primordial criado pela União a fim de induzir a ação legal pelos municípios foi o Plano de Ações Articuladas (PAR).

Os dados levantados nesta pesquisa apontam que o PAR tem desempenhado importante papel na indução dos entes federativos locais em relação à regulamentação das normativas atinentes à valorização docente, principalmente no que se refere à elaboração de planos de carreira e cumprimento com os preceitos da "Lei do Piso", no entanto, o estabelecimento do compromisso por parte dos municípios nem sempre se reverte em ações efetivas voltadas ao seu cumprimento, de forma que a articulação dos movimentos sociais tem se revelado crucial para a garantia dessas conquistas.

\section{Referências}

ALVES, T.; PINTO, J. M. de R. Remuneração e características do trabalho docente no Brasil: um aporte. Cadernos de Pesquisa. São Paulo, v. 41, n. 143, p. 606-639, maio/jun. 2011.

ARAÚJO, V.Prefeitura terá que trocar 848 servidores sem concurso.O Progresso. Dourados, MS, 11/06/2015. Disponível em http://www.progresso.com.br/dia-a-dia/prefeitura-tera-que-trocar-848-servidores-sem-concurso. Acesso em 20/01/2016.

BALZANO, S. O desafio da profissionalização docente no Brasil e na América Latina. Brasília: CONSED/ UNESCO, 2007.

BRASIL. Congresso Nacional. Constituição da República Federativa do Brasil. Brasília: Senado Federal, Centro gráfico, 1988. 
Plano de Metas Compromisso Todos pela Educação: Guia de Programas. Brasília: MEC, 2007. Compromisso Todos pela Educação: passo a passo. Brasília: SEB/MEC, 2008a.

. Lei n. 11.494, de 20 de junho de 2007. Regulamenta o Fundo de Manutenção e Desenvolvimento da Educação Básica e de Valorização dos Profissionais da Educação - FUNDEB, de que trata o art. 60 do Ato das Disposições Constitucionais Transitórias e, dá outras providências. Diário Oficial da União, Poder legislativo, Brasília, DF, 20 de jun. de 2007a. Disponível em: <http://www.planalto.gov.br/ccivil_03/_Ato20072010/2007/Lei/ L11738.htm>. Acesso em: mar. de 2014. 178

. Lei n. 11.738, de 16 de julho de 2008b. Regulamenta e Institui o Piso Salarial Profissional Nacional para os profissionais do magistério público da educação básica. Diário Oficial da União, Poder legislativo, Brasília, DF, 16 de jul. de 2008b. Disponível em: <http://www.planalto.gov.br/ccivil/_Ato2007-2010/2008/Lei/ L11738.htm>. Acesso em: abr. de 2014.

Ministério da Educação. Orientações para elaboração do plano de ações articuladas (PAR) dos municípios (2011-2014). Brasília: MEC, 2011.

CORUMBÁ. Lei Complementar NN 150 de 4 de abril de 2012. Institui o Plano de Carreira e Remuneração do Magistério Municipal de e dispõe sobre direitos, vantagens e obrigações de seus integrantes. Corumbá, MS, 2012. Plano de Ações Articuladas (2011 - 2014). Corumbá, MS, 2011.

COXIM. Plano de Ações Articuladas (2011 - 2014). Coxim, MS, 2011.

Lei Complementar nº 023 de 27/04/2000. Dispõe sobre o Plano de Cargos, Carreiras e Remuneração do Grupo Trabalhadores da Educação Básica de Coxim-MS e Anexos, e dá outras providências. Coxim, MS, 2000.

DOURADOS. Lei complementar n. 118 de 31 de dezembro de 2007. Dispõe sobre o Plano de Cargos, Carreira e Remuneração do Profissional da Educação Municipal de Dourados. Dourados, MS, 2007.

. Plano de Ações Articuladas (2011 - 2014). Dourados, MS, 2011.

DRAIBE, S. M. Avaliação de implementação: o esboço de uma metodologia de trabalho em políticas públicas. In: BARREIRA, M. C. R. N.; CARVALHO, M. C. B. (Orgs.). Tendências e perspectivas na avaliação de políticas e programas sociais.São Paulo: IEE/PUC-CP, 2001.

DUARTE, A. W. B. Por que ser professor? Uma análise da carreira docente na educação básica no Brasil.2013.147f. Dissertação (Mestrado em Educação) - Faculdade de Educação. Universidade Federal de Minas Gerais, Minas Gerais, 2013.

FERREIRA,E. B. Federalismo e planejamento educacional no exercício do par.Cadernos de Pesquisa, vol.44, no.153. São Paulo. Jul/Set. 2014.

FETEMS. Federação dos Trabalhadores em Educação de Mato Grosso do Sul. Ranking salarial do Magistério de Mato Grosso do Sul. Campo Grande, MS: FETEMS, 2015. Disponível no site [http://www.fetems.org.br/novo/ detalheArquivo. php?sect=9\&file=634]. Acesso em 13 de janeiro de 2016.

FETEMS. Federação dos Trabalhadores em Educação de Mato Grosso do Sul.FETEMS na Estrada: Piso Salarial Nacional é tema de debate em Ponta Porã. Campo Grande, MS: FETEMS, 2013. Disponível no site [http:// www.fetems.org.br/novo/nw.php?nw=5130]. Acesso em 13 de janeiro de 2016.

GATTI, B. et all. Atratividade da carreira docente no Brasil. São Paulo: Fundação Carlos Chagas, 2009.

GATTI, B.; BARRETTO, E. S. de S. (Coords.). Professores no Brasil: impasses e desafios. Brasília: UNESCO, 2009.

KUENZER, A.; CALDAS, A. Trabalho docente: comprometimento e desistência. In: FIDALGO, Fernando, OLIVEIRA, Maria Auxiliadora M., FIDALGO, Nara Luciene Rocha (Orgs): A Intensificação do Trabalho Docente: tecnologias e produtividades. Campinas, SP: Papirus, 2009.

MACHADO, J. P. Piso Salarial Profissional Nacional do Magistério: conflitos e limites de sua implantação na rede pública estadual de Goiás. 2010. 219f. Dissertação (Mestrado em Educação) - Faculdade de Educação. Universidade Federal de Goiás, Goiânia, 2010. 
MIDIAMAX.MPE recomenda que prefeito de Ponta Porã abra concurso público para professores. Campo Grande, MS, 11/09/2014. Disponível em http://www.midiamax.com.br/noticias/927942-mpe-recomenda-queprefeito-de-ponta-pora-abra-concurso-publico-para-professores.html. Acessado em 20/01/2015.

NAVIRAÍ.Lei Complementar no 110 de 15 de dezembro de 2011. Dispõe sobre o Estatuto dos Profissionais da Educação Básica do Município de Naviraí. Naviraí, MS, 2011.

. Plano de Ações Articuladas (2011 - 2014). Naviraí, MS, 2011.

PONTA PORÃ. Lei Complementar n ${ }^{\circ} 029$ de 04 de janeiro de 2006. Dispõe sobre o Plano de Cargos, Carreiras e Remuneração dos servidores do Magistério Municipal do Quadro Permanente da Prefeitura Municipal de Ponta Porã. Ponta Porã, MS, 2006.

. Plano de Ações Articuladas (2011 - 2014). Ponta Porã, MS, 2011.

Recebido em Junho de 2016 | Aprovado em Outubro de 2016 